\title{
Development and Validation of a RP-HPLC Method to Quantify Amoxicillin, Tinidazole, Esomeprazole and Lan- soprazole in a Mixture
}

\author{
M. SMERIKAROVA*, S. BOZHANOV AND V. MASLARSKA \\ Department of Chemistry, Faculty of Pharmacy, Medical University of Sofia, 2 Dunav st., 1000 Sofia, Bulgaria
}

\begin{abstract}
Smerikarova et al.: RP-HPLC Method to Estimate Amoxicillin, Tinidazole, Esomeprazole and Lansoprazole
Present investigation dealt with the developing of a reversed phase-high performance liquid chromatographic method for determination of amoxicillin, tinidazole, esomeprazole and lansoprazole in pure state and as a mixture. Chromatographic separation was performed isocratically on a LiChrospher ${ }^{\circledR} 100 \mathrm{RP}-18$ column. The flow rate was $1.0 \mathrm{ml} / \mathrm{min}$ and the detector was set at $280 \mathrm{~nm}$. The method was developed at ambient temperature with a mobile phase, 40:60 v/v acetonitrile and phosphate buffer $(0.001 \mathrm{M}, \mathrm{pH} 7.6)$. The selected conditions were applicable for separating amoxicillin, tinidazole, esomeprazole and lansoprazole with retention times $3.11,5.37,11.71$ and $17.67 \mathrm{~min}$, respectively. The method was validated for parameters including linearity, selectivity, precision and accuracy, limit of detection and limit of quantitation. Linear calibration curves were obtained in the concentration range of $250.0-2000.0,125-1000.0,5.0-40.0$ and $7.5-$ $60.0 \mu \mathrm{g} / \mathrm{ml}$ for amoxicillin, tinidazole, esomeprazole and lansoprazole, respectively. The proposed method was found to be effective and could be used for quantification of these drugs in routine quality control practice.
\end{abstract}

Key words: Helicobacter pylori, HPLC, drug analysis, chromatography, gastrointestinal diseases

Peptic ulcer disease (gastric and duodenal), chronic gastritis and other upper gastrointestinal tract problems are among the most common conditions caused by infection with Helicobacter pylori. This Gramnegative, microaerophilic stomach pathogen, which colonizes the human gastric mucosa is increasingly difficult to treat ${ }^{[1]}$. First-line eradication therapy should be carefully selected, pertinent and based on the local resistance rates of the antibiotic constituents. The best tolerated and safest therapy is clarithromycin (CLA) triple therapy containing CLA, one of the proton pump inhibitors (PPIs) and amoxicillin (AMOX) or metronidazole (MET). Although the aim is to obtain a highest eradication rate, antibiotic resistance is the most important reason which leads to first-line therapy failure ${ }^{[2]}$. A regional variation in antibiotic resistance is observed, with prevalence to CLA and MET, as a part of the major triple therapy ${ }^{[1,2]}$. This requires a new approach to the therapy and selection of a drug combination suitable for patients with antibiotic-resistant $H$. pylori infection. Lots of literature articles summarized various therapeutic directions and regimens for eradication of

*Address for correspondence

E-mail: m.smerikarova@pharmfac.mu-sofia.bg
H. pylori ${ }^{[3,4]}$. Among them is the triple therapy with AMOX, nitroimidazole derivative and one PPI. In case of resistance to MET, it can be replaced by tinidazole (TIN). There are some papers in the literature suggested that esomeprazole (ESOM) may be more effective than other PPIs and have the most rapid action followed by lansoprazole (LAN) $)^{[5,6]}$.

Different methods like HPLC ${ }^{[7-16]}$ UV spectrophotometry ${ }^{[17-25]}$ and capillary electrophoresis ${ }^{[26-30]}$ were developed for determination of these drugs alone ${ }^{[7-10,19,30]}$ or in combinations with other drugs $^{[12-18,20-23,24-29]}$. Some methods for determination of AMOX and TIN simultaneously were reported ${ }^{[12-15]}$ but to the best of our knowledge there is no published method for simultaneous determination of AMOX, TIN

This is an open access article distributed under the terms of the Creative Commons Attribution-NonCommercial-ShareAlike 3.0 License, which allows others to remix, tweak, and build upon the work non-commercially, as long as the author is credited and the new creations are licensed under the identical terms

Accepted 04 September 2019 Revised 02 May 2019 Received 16 March 2019 Indian J Pharm Sci 2019;81(6):1122-1127 
and a PPI. Therefore the aim of this study is to develop a method, which would be able to separate and quantify a combination of AMOX, TIN, ESOM and LAN in a single run.

All chemicals and reagents used for method developing were HPLC grade. AMOX, TIN, ESOM and LAN standards were obtained from Sigma-Aldrich. HPLC grade acetonitrile was purchased from Fisher Chemicals. Microcrystalline cellulose, talc, starch, and magnesium stearate were used as excipients. All other chemical reagents were of analytical grade.

A high performance liquid chromatographic system (Shimadzu, LC-20 AD quaternary pump) with an auto sampler, Shimadzu DGU-20A 5 vacuum degasser and a Shimadzu SPD-20A UV/Vis detector was used for analysis. The data were recorded using Lab Solutions software. Separation was carried out at ambient temperature $\left(25^{\circ}\right)$, using LiChrospher ${ }^{\circledR} 100$ RP-18 $(250 \times 4 \mathrm{~mm}, 5 \mu \mathrm{m})$ column. The mobile phase, $40: 60 \mathrm{v} / \mathrm{v}$ acetonitile: $0.001 \mathrm{M}$ phosphate buffer $\mathrm{pH}=7.6$, was filtered and then sonicated for $10 \mathrm{~min}$. The detector was set at $280 \mathrm{~nm}$. Analysis was performed by isocratic elution with a flow rate $1.0 \mathrm{ml} / \mathrm{min}$ and $20 \mu \mathrm{l}$ injection volume. Typical chromatograms of standard solution and synthetic mixture were shown in fig. 1 .

The buffer solution was prepared by dissolving $0.136 \mathrm{~g}$ potassium dihydrogen phosphate in $1000 \mathrm{ml}$ of water and the $\mathrm{pH}$ was adjusted to 7.6 with $0.1 \mathrm{M}$ sodium hydroxide. Stock standards were prepared by dissolving of $1000 \mathrm{mg}$ AMOX, $500 \mathrm{mg}$ TIN, $20 \mathrm{mg}$ ESOM and $30 \mathrm{mg}$ LAN (accurately weighed) each in the mobile phase in 4 separate 100-ml volumetric flasks. The stock solutions were further diluted with mobile phase $(10 \mathrm{ml}$ of each solution in $100 \mathrm{ml}$ volumetric flask) to produce working standard solution with concentration of $1 \mathrm{mg} / \mathrm{ml}$ of AMOX and $0.5 \mathrm{mg} / \mathrm{ml}$ of TIN, $0.02 \mathrm{mg} / \mathrm{ml}$ of ESOM and $0.03 \mathrm{mg} / \mathrm{ml}$ of LAN, respectively.

A physical mixture was prepared by mixing accurately weighed $1000 \mathrm{mg}$ AMOX, $500 \mathrm{mg}$ TIN, $20 \mathrm{mg}$ ESOM and $30 \mathrm{mg}$ LAN with excipients such as microcrystalline cellulose $50 \mathrm{mg}$, talc $5 \mathrm{mg}$, starch $50 \mathrm{mg}$ and magnesium stearate $5 \mathrm{mg}$ and homogenised well. A portion of powder equivalent to $500 \mathrm{mg}$ AMOX, $250 \mathrm{mg}$ TIN, $10 \mathrm{mg}$ ESOM and $15 \mathrm{mg}$ LAN was transferred to a $100 \mathrm{ml}$ volumetric flask, $50 \mathrm{ml}$ of mobile phase was added and then sonicated for $10 \mathrm{~min}$. The suspension was made up to the volume with mobile phase. An aliquot portion of the filtrate was further diluted to get a final concentration of $1 \mathrm{mg} / \mathrm{ml}$ of AMOX and $0.5 \mathrm{mg} / \mathrm{ml}$ of

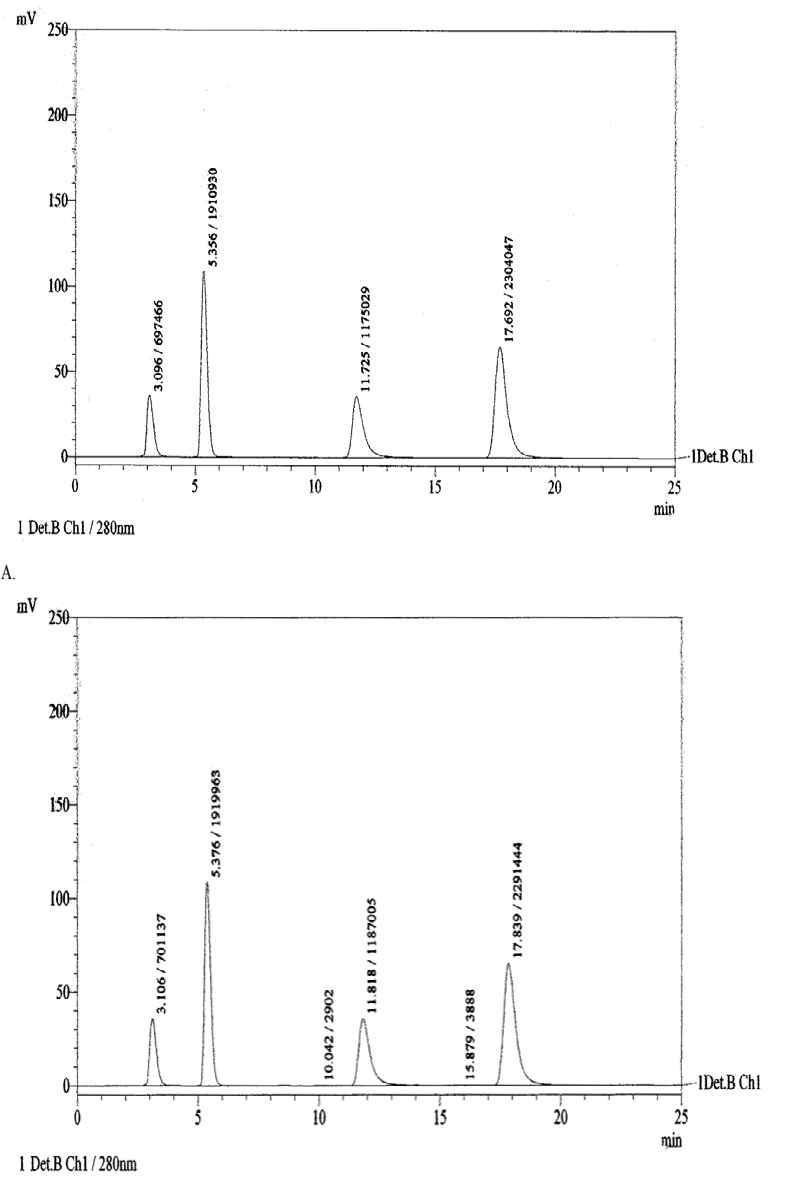

B.

Fig. 1: Typical chromatograms of standard and sample analytes Chromatogram of A. standard AMOX, TIN, ESOM and LAN and $B$. of the test samples AMOX, TIN, ESOM and LAN

TIN, $0.02 \mathrm{mg} / \mathrm{ml}$ of ESOM and $0.03 \mathrm{mg} / \mathrm{ml}$ of LAN, respectively.

The proposed method was validated in terms of selectivity linearity, accuracy, precision and limits of detection and quantitation according to $\mathrm{ICH}$ guidelines $^{[31]}$. One analytical procedure is validated for linearity when the test results provided with it, within a given range are proportional of the concentration of active substances in the samples. It is recommended to analyse at least 5 standard solutions with increasing concentrations to establish the linearity of the method. Each standard solution is injected 6 times and the mean results for peak areas are plotted on graphics against concentration of the analytes. The parameter whose limits are monitored is correlation coefficient $\left(\mathrm{R}^{2}\right)$. Its value should be greater than 0.999 .

The accuracy showed the closeness between true value and the value found with the current analytical procedure. The percent recovery is calculated after analysing 3 concentration levels with known added amount of analyte and 3 replicates of the procedure. 
The analytical procedure was applied to the standard solutions of the drugs or the synthetic mixture.

The precision of an analytical procedure is established by analysing multiple samples. The results from the series of measurements of the same homogeneous samples should be obtained in the same conditions. The main parameters expressing precision of the method are variance and standard deviation (SD). The three levels of precision are intra-day precision (repeatability), inter-day precision and precision between laboratories (reproducibility). Repeatability is assessed by performing 6 determinations of $100 \%$ of the test concentration.

Limit of detection(LOD) and limit of quantitation(LOQ) are required for validating of an analytical procedure. LOD is defined as the lowest amount of analyte in a sample which can be detected. It is not necessary this amount to be quantitated. LOQ is the lowest amount of the analyte, which can be quantitatively determined. There are 3 ways to determine LOD or LOQ, based on visual evaluation, based on signal to noise ratio and based on the SD of the response and the slope. With the last method LOD is expressed as, $\mathrm{LOD}=3.3 \mathrm{\sigma} / \mathrm{S}$, where $\sigma$ is the standard deviation of the response and $S$ is the slope of the calibration curve. And LOQ is expressed as, $L O Q=10 \sigma / S$, where $\sigma$ is the standard deviation of the response and $\mathrm{S}$ is the slope of the calibration curve. Sufficient number of samples with concentrations near the quantitation limit is analysed and the obtained results are used for validation of the analytical procedure.

This RP-HPLC method was developed for identifying and separating 4 drugs mostly prescribed for $H$. pylori therapy. Standard first line therapy included three of them AMOX, TIN and one of the PPIs, but this method allowed inclusion and determination of one more PPI. Several stationary phase and mobile phase combinations were tried in the process of developing of the method. As a stationary phase were tried C 8 and $\mathrm{C} 18$ columns. Mobile phases consisted of organic and nonorganic solvents in varying ratios and composition were applied with the different stationary phases. Methanol and acetonitrile were the organic solvents used in the process of optimizing the content of mobile phase but as non-organic solvent was used only phosphate buffer. Factors like flow rate $(0.7-1.0 \mathrm{ml} / \mathrm{min})$, temperature (ambient and $40^{\circ}$ ), wavelength and $\%$ of buffer solution and $\mathrm{pH}$ of the mobile phase were changed successively to optimize the HPLC conditions. Retention times obtained for AMOX and TIN are comparable with previously reported ${ }^{[11]}$. The percent organic solvent used in the mobile phase was smaller than in the other previously developed methods ${ }^{[9-11]}$, which also can be determined as an advantage. LOD and LOQ obtained with our method were comparable with these obtained with other methods ${ }^{[16]}$. To provide reproducible results some system suitability parameters were checked after repetitively injecting of the drug solutions with concentrations 1000, 500, 20 and $30 \mu \mathrm{g} / \mathrm{ml}$ for AMOX, TIN, ESOM and LAN, respectively. Results obtained for system suitability and method validation are shown in Table 1.

Selectivity of the method was demonstrated by good separation of AMOX, TIN, ESOM and LAN. Furthermore, matrix components, e.g. excipients, did not interfere with the analytes. A placebo sample was prepared by dissolving microcrystalline cellulose 50 $\mathrm{mg}$, talc $5 \mathrm{mg}$, starch $50 \mathrm{mg}$ and magnesium stearate $5 \mathrm{mg}$ in $100 \mathrm{ml}$ volumetric flask with the same diluent as the synthetic mixture. No peak was detected at the retention time of AMOX, TIN, ESOM and LAN hence proving the specificity of the method.

\section{TABLE 1: SYSTEM SUITABILITY AND VALIDATION PARAMETERS}

\begin{tabular}{lcccc}
\hline Parameters & AMOX & TIN & ESOM & LAN \\
\hline $\begin{array}{l}\text { Retention time } \\
\text { (min) }\end{array}$ & 3.10 & 5.36 & 11.73 & 17.69 \\
Theoretical plates & 2035.5 & 2117.2 & 3391.5 & 6437.8 \\
Tailing factor & 1.49 & 1.35 & 1.76 & 1.54 \\
Resolution & 0.00 & 4.70 & 2.52 & 2.62 \\
Capacity factor & 0.00 & 0.73 & 2.79 & 4.71 \\
$\left(K^{\prime}\right)$ & 0.46 & 1.07 & 0.51 \\
Precision, \% RSD & 0.31 & 1.4 & 0.6 & 0.5 \\
LOD $(\mu \mathrm{g} / \mathrm{ml})$ & 2.8 & 4.1 & 1.8 & 1.6 \\
LOQ $(\mu \mathrm{g} / \mathrm{ml})$ & 8.4 & Stable & Stable & Specific \\
Specificity & no interference & Specific, no interference & Specific, no interference \\
Stability & Stable & Specific, no interference
\end{tabular}

AMOX is amoxicillin, TIN is tinidazole, ESOM is esomeprazole and LAN is lansoprazole. SE is the standard error of the mean, SD is standard deviation for $n=3$ observations, the mobile phase used was 40:60 v/v of acetonitrile:0.001 M phosphate buffer $\mathrm{pH}=7.6$ 
TABLE 2: LINEARITY DATA FOR AMOX, TIN, ESOM AND LAN

\begin{tabular}{lcccc}
\hline Parameters & AMOX & TIN & ESOM & LAN \\
\hline Concentration, $(\mu \mathrm{g} / \mathrm{ml})$ & $250.0-2000.0$ & $125-1000.0$ & $5.0-40.0$ & $7.5-60.0$ \\
Correlation coefficients $\left(\mathrm{R}^{2}\right)$ & 0.9994 & 0.9995 & 0.9995 & 0.9994 \\
SE of intercept & 13092.5 & 35684.5 & 24058.0 & 28101.6 \\
SD of intercept & 5855.1 & 15958.4 & 10758.9 & 12567.2 \\
\hline
\end{tabular}

LOD is limit of detection and LOQ is limit of quantitation

TABLE 3: RESULTS OF RECOVERY STUDIES

\begin{tabular}{|c|c|c|c|c|c|c|c|c|}
\hline Drug & $\begin{array}{c}\text { Recovery } \\
\text { level }\end{array}$ & $\begin{array}{l}\text { Drug taken } \\
\qquad(\mu \mathrm{g} / \mathrm{ml})\end{array}$ & $\begin{array}{c}\text { Standard } \\
\text { drug added } \\
(\mu \mathrm{g} / \mathrm{ml})\end{array}$ & $\begin{array}{c}\text { Total conc. } \\
\text { of drug } \\
(\mu g / m l)\end{array}$ & $\begin{array}{c}\text { Total amount } \\
\text { recovered } \\
(\mu \mathrm{g} / \mathrm{ml})\end{array}$ & $\%$ Recovery & Mean \pm SD & \% RSD \\
\hline & 80 & 1000 & 800 & 1800 & 1796.70 & 99.82 & & \\
\hline & 80 & 1000 & 800 & 1800 & 1791.21 & 99.51 & & \\
\hline & 80 & 1000 & 800 & 1800 & 1802.32 & 100.13 & & \\
\hline & 100 & 1000 & 1000 & 2000 & 2010.51 & 100.53 & & \\
\hline \multirow[t]{9}{*}{$\mathrm{AMOX}^{*}$} & 100 & 1000 & 1000 & 2000 & 2006.64 & 100.33 & $100.04 \pm 0.3128$ & $0.3126 \%$ \\
\hline & 100 & 1000 & 1000 & 2000 & 2001.30 & 100.07 & & \\
\hline & 120 & 1000 & 1200 & 2200 & 2199.65 & 99.98 & & \\
\hline & 120 & 1000 & 1200 & 2200 & 2194.53 & 99.75 & & \\
\hline & 120 & 1000 & 1200 & 2200 & 2204.81 & 100.22 & & \\
\hline & 80 & 500 & 400 & 900 & 905.92 & 100.66 & & \\
\hline & 80 & 500 & 400 & 900 & 897.00 & 99.67 & & \\
\hline & 80 & 500 & 400 & 900 & 899.93 & 99.99 & & \\
\hline & 100 & 500 & 500 & 1000 & 993.03 & 99.30 & & \\
\hline \multirow[t]{9}{*}{ TIN* $^{*}$} & 100 & 500 & 500 & 1000 & 993.72 & 99.37 & $99.92 \pm 0.4595$ & $0.4598 \%$ \\
\hline & 100 & 500 & 500 & 1000 & 997.84 & 99.78 & & \\
\hline & 120 & 500 & 600 & 1100 & 1098.81 & 99.89 & & \\
\hline & 120 & 500 & 600 & 1100 & 1101.61 & 100.15 & & \\
\hline & 120 & 500 & 600 & 1100 & 1105.30 & 100.48 & & \\
\hline & 80 & 20 & 16 & 36 & 35.86 & 99.61 & & \\
\hline & 80 & 20 & 16 & 36 & 35.71 & 99.19 & & \\
\hline & 80 & 20 & 16 & 36 & 35.56 & 98.78 & & \\
\hline & 100 & 20 & 20 & 40 & 40.63 & 101.58 & & \\
\hline \multirow[t]{9}{*}{$\mathrm{ESOM}^{*}$} & 100 & 20 & 20 & 40 & 39.28 & 98.20 & $99.18 \pm 1.0613$ & $1.0701 \%$ \\
\hline & 100 & 20 & 20 & 40 & 39.50 & 98.75 & & \\
\hline & 120 & 20 & 24 & 44 & 43.37 & 98.57 & & \\
\hline & 120 & 20 & 24 & 44 & 43.90 & 99.77 & & \\
\hline & 120 & 20 & 24 & 44 & 43.19 & 98.16 & & \\
\hline & 80 & 30 & 24 & 54 & 53.52 & 99.11 & & \\
\hline & 80 & 30 & 24 & 54 & 54.22 & 100.41 & & \\
\hline & 80 & 30 & 24 & 54 & 54.08 & 100.15 & & \\
\hline & 100 & 30 & 30 & 60 & 60.20 & 100.33 & & \\
\hline \multirow[t]{5}{*}{$\mathrm{LAN}^{*}$} & 100 & 30 & 30 & 60 & 60.47 & 100.78 & $100.08 \pm 0.5076$ & $0.5072 \%$ \\
\hline & 100 & 30 & 30 & 60 & 59.93 & 99.88 & & \\
\hline & 120 & 30 & 36 & 66 & 66.31 & 100.47 & & \\
\hline & 120 & 30 & 36 & 66 & 65.98 & 99.97 & & \\
\hline & 120 & 30 & 36 & 66 & 65.72 & 99.58 & & \\
\hline
\end{tabular}

*Average of three independent procedures

Linearity was established by analysing a series of solutions prepared by diluting the stock solution with mobile phase. Five concentrations were chosen ranging between $250-2000 \mu \mathrm{g} / \mathrm{ml}$ for AMOX, 125-1000 $\mu \mathrm{g} / \mathrm{ml}$ for TIN, $5-40 \mu \mathrm{g} / \mathrm{ml}$ for ESOM and $7.5-60 \mu \mathrm{g} / \mathrm{ml}$ for LAN. Each concentration was triplicate injected and the correlation coefficients were found to be more than
0.999 for all the analytes and the results are shown in Table 2. The experiments for accuracy of the method were performed by adding known amounts of the drugs in the secondary stock solutions for AMOX and TIN with 1000 and $500 \mu \mathrm{g} / \mathrm{ml}$ concentrations, respectively and in the stock solutions for ESOM and LAN with concentrations 20 and $30 \mu \mathrm{g} / \mathrm{ml}$, respectively. There 
were three levels of recovery 80,100 and $120 \%$ for each of the described concentrations. Three samples for each recovery level were analysed and the results of the recovery studies were summarized in Table 3.

LOD and LOQ were determined by using signal to noise ratio. As the lowest concentration which can be detected at a specified level of confidence, LOD for AMOX, TIN, ESOM and LAN was 2.8, 1.4, 0.6 and $0.5 \mu \mathrm{g} / \mathrm{ml}$, respectively. After some repeated dilutions LOQ, as the lowest determined concentration was measured for AMOX, TIN, ESOM and LAN was 8.4, $4.1,1.8$ and $1.6 \mu \mathrm{g} / \mathrm{ml}$, respectively.

The precision data for this method was represented by calculating the $\%$ RSD for the 4 separated drugs. Nine samples of the standard solutions were analysed and the $\%$ RSD was found to be $0.3126,0.4598,1.0701$ and $0.5072 \%$ for AMOX, TIN, ESOME and LAN, respectively. All values were within the limits and this validated the method as precise.

An accurate, sensitive and precise HPLC method for the simultaneous determination of amoxicillin, tinidazole and esomeprazole and lansoprazoel was developed. The advantage of this method is that it enables determination of all 4 drugs simultaneously. The method could be used for routine quality control analysis of bulk drug and synthetic mixtures.

\section{Acknowledgements:}

This work is supported by the Bulgarian Ministry of Education and Science under the National Program for Research "Young Scientists and Postdoctoral Students".

\section{REFERENCES}

1. Safavi M, Sabourian R, Foroumadi A. Treatment of Helicobacter pylori Infection: Current and Future Insights. World J Clin Cases 2016;4(1):5-19.

2. Ansari S, Yamaoka Y. Current Understanding and Management of Helicobacter pylori infection: an updated appraisal. F1000Res 2018;7:721.

3. Puig I, Baylina M, Sanchez-Delgado J, Lopez-Gongora S, Suarez D, Garcia-Iglesias P, et al. Systematic Review and MetaAnalysis: Triple Therapy Combining a Proton-Pump Inhibitor, Amoxicillin and Metronidazole for Helicobacter pylori FirstLine Treatment. J Antimicrob Chemother 2016;71:2740-53.

4. Lee HJ, Kim JI, Lee JS, Jun EJ, Oh JH, Cheung DY, et al. Concomitant Therapy Achieved the Best Eradication Rate for Helicobacter pylori Among Various Treatment Strategies. World J Gastroenterol 2015;21(1):351-9.

5. Zheng RN. Comparative Study of Omeprazole, Lansoprazole, Pantoprazole and Esomeprazole for Symptom Relief in Patients with Reflux Esophagitis. World J Gastroenterol 2009;15(8):990-5.

6. Celebi A, Aydin D, Kocaman O, Konduk BT, Şenturk O, November-December 2019 Indian Journal of Pharmaceutical Sciences
Hulagu S. Comparison of the Effects of Esomeprazole $40 \mathrm{mg}$, Rabeprazole $20 \mathrm{mg}$, Lansoprazole $30 \mathrm{mg}$, and Pantoprazole $40 \mathrm{mg}$ on Intragastric $\mathrm{pH}$ in Extensive Metabolizer Patients with Gastroesophageal Reflux Disease. Turk J Gastroenterol 2016;27:408-14.

7. Hoizey G, Lamiable D, Frances C, Trenque T, Kaltenbach M, Denis $\mathrm{J}$, et al. Simultaneous Determination of Amoxicillin and Clavulanic Acid in Human Plasma by HPLC with UV Detection. J Pharm Biomed Anal 2002;30:661-6.

8. Usha Rani N, Seshagiri Rao JVLN. Estimation of Tinidazole in Tablets by RP-HPLC Method. Int J Chem Sci 2010;8(4):232530.

9. Khalil MT, Usman M, Khan GM, Awan SB, Bibi H, Siddiqua A. HPLC Method Development and Validation for the Estimation of Esomeprazole in Bulk and Pharmaceutical Dosage Form. Int J Drug Dev Res 2012;4(4):252-6.

10. Kumar SM, Kumar DS, Rajkumar T, Kumar EU, Geetha AS, Diwedi D. Development and Validation of RP-HPLC Method for the Estimation of Lansoprazole in Tablet Dosage Form. J Chem Pharm Res 2010;2(6):291-5.

11. Bojaraju V, Sireesha D, Prasad VVLN, Diwan PV. Reverse Phase High Performance Liquid Chromatography Method for the Simultaneous Estimation of Amoxicillin Trihydrate and Tinidazole in the Tablet Dosage Form. World J Chem 2012;7(2):47-52.

12. Sirisha T, Gurupadayya BM, Sridhar S. Simultaneous Determination of Ciprofloxacin and Tinidazole in Tablet Dosage Form by Reverse Phase High Performance Liquid Chromatography. Trop J Pharm Res 2014;13(6):981.

13. Ouyang LQ, Wu HL, Liu YJ, Wang JY, Yu YJ, Zou HY, et al. Simultaneous Determination of Metronidazole and Tinidazole in Plasma by Using HPLC-DAD Coupled with Second-Order Calibration. Chin Chem Lett 2010;21:1223-6.

14. Raghunath M, Dhamne A. RP-HPLC Method for Simultaneous Estimation of Ciprofloxacin, Tinidazole and Dicyclomine in Bulk and Tablet Dosage Form. J Parm Res 2015;14(3):66-70.

15. Houshe S, Bachour G, Chehna MF. Development of Rapid and Simple Analytical Method for Some Proton Pump Inhibitors (PPIs) Using HPLC. Jordan J Pharm Sci 2011;4(3):222-36.

16. Solanki R, Nagori BP, Naval MK, Banerjee J. Development and Validation of Simultaneous Estimation Method for Amoxycillin Trihydrate and Tinidazole in Tablet Dosage Form by RP-HPLC. Asian J Pharm Anal 2013;3(2):66-71.

17. Gujral RS, Haque SM. Simultaneous Determination of Potassium Clavulanate and Amoxicillin Trihydrate in Bulk, Pharmaceutical Formulations and in Human Urine Samples by UV Spectrophotometry. Int J Biomed Sci 2010;6(4):335-43.

18. Attia KAM, Nassar MWI, El-Zeiny MB, Serag A. Different Spectrophotometric Methods Applied for the Analysis of Binary Mixture of Flucloxacillin and Amoxicillin: A Comparative Study. Spectrochim Acta Part A2016;161:64-9.

19. Othman NS, AL-Saffar RS. Spectrophotometric Determination of Amoxicillin in Pharmaceutical Preparations. Int J Enhanced Res Sci Tech Eng 2015;4(6):167-73.

20. Manu JS, Yogesh AS, Randhir CB, Manoj BM, Barhate SD. UV Spectrophotometric Methods for Simultaneous Estimation of Levosulpiride and Esomeprazole in Capsule Dosage Form. Asian J Pharm Anal 2012;2(4):106-9.

21. Jain N, Kulkarni S, Jain DK, Jain SK. Spectrophotometric Methods for Simultaneous Estimation of Esomeprazole Magnesium and Naproxen in a Tablet Dosage Form. Acta Poloniae Pharm Drug Res 2012;69(6):1195-9.

22. Sojitra R, Pathak A, Rajput S. Development and Validation 1126 
of Spectrophotometric Methods for Simultaneous Estimation of Naproxen and Esomeprazole Magnesiumtrihydrate in Combined Pharmaceutical Formulation. Int J Chem Tech Res 2012;4(2):602-8.

23. Nassar MY, El-Shahat MF, Khalil SM, El-Moety EA. Optimization and Validation of Spectrophotometric and Potentiometric Methods for Determination of Lansoprazole and Omeprazole in Pure and Capsules. Indian J Pharm Sci 2017;79(3):420-30.

24. Nayak K, Khare NK, Sayare A, Ghode P, Lawrence RM. New Validated UV Spectrophotometric Methods for Estimation of Norfloxacin and Tinidazole in Bulk and Tablet Dosage Forms. Der Pharm Lett 2012;4(1):192-8.

25. Darwish KM, Salama I, Mostafa S, El-Sadek M. Extractional Spectrophotometric Analysis of Metronidazole, Tinidazole, Ornidazole and Secnidazole Bases Through Acid-Dye Complexation Using Bromothymol Blue Dye. Pak J Pharm Sci 2012;25(1):207-17.

26. Oliva DC, Vélez KT, Vázquez ALR. Simultaneous Determination of Bromhexine and Amoxicillin in Pharmaceutical Formulations by Capillary Electrophoresis. J Mex Chem Soc 2011;55(2):79-83.

27. Hancu G, Neacşu A, Papp LA, Ciurba A. Simultaneous Determination of Amoxicillin and Clavulanic Acid in Pharmaceutical Preparations by Capillary Zone Electrophoresis. Braz J Pharm Sci 2016;52(2):281-6.

28. Lin $\mathrm{Y}, \mathrm{Su} \mathrm{Y}$, Liao $\mathrm{X}$, Yang N, Yang $\mathrm{X}$, Choi MMF. Determination of Five Nitroimidazole Residues in Artificial Porcine Muscle Tissue Samples by Capillary Electrophoresis. Talanta 2012;88:646-52.

29. Marra MS, Cunha RR, Munoz RAA, Batista AD, Richter EM. Single-Run Capillary Electrophoresis Method for the Fast Simultaneous Determination of Amoxicillin, Clavulanate, and Potassium. J Sep Sci 2017;40(17):3557-62.

30. Estevez P. Flor S, Boscolo O, Tripodi V, Lucangioli S. Development and Validation of a Capillary Electrophoresis Method for Determination of Enantiomeric Purity and Related Substances of Esomeprazole in Raw Material and Pellets. Electrophoresis 2014;35(6):804-10.

31. International Conference on Harmonisation of Technical Requirements for Registration of Pharmaceuticals for Human Use, ICH Harmonised Tripartite Guideline, Validation of Analytical Procedures: Text and Methodology Q2(R1), Current Step 4 version, November 2005. Available from: https://www. ema.europa.eu/en/documents/scientific-guideline/ich-q-2-r1validation-analytical-procedures-text-methodology-step-5 en.pdf. 